\title{
GMR
}

\section{Selection of morphoagronomic descriptors for the characterization of accessions of cassava of the Eastern Brazilian Amazon}

\author{
R.S. Silva ${ }^{1}$, E.F. Moura ${ }^{2}$, J.T. Farias-Neto ${ }^{2}$, C.A.S. Ledo ${ }^{3}$ and J.E. Sampaio ${ }^{2}$ \\ ${ }^{1}$ Universidade Federal Rural da Amazônia, Belém, PA, Brasil \\ ${ }^{2}$ Embrapa Amazônia Oriental, Belém, PA, Brasil \\ ${ }^{3}$ Embrapa Mandioca e Fruticultura, Cruz das Almas, BA, Brasil \\ Corresponding author: E.F. Moura \\ E-mail: elisa.moura@embrapa.br \\ Genet. Mol. Res. 16 (2): gmr16029595 \\ Received December 22, 2016 \\ Accepted February 23, 2017 \\ Published April 13, 2017 \\ DOI http://dx.doi.org/10.4238/gmr16029595 \\ Copyright (C) 2017 The Authors. This is an open-access article distributed under the terms of \\ the Creative Commons Attribution ShareAlike (CC BY-SA) 4.0 License.
}

\begin{abstract}
The aim of this study was to select morphoagronomic descriptors to characterize cassava accessions representative of Eastern Brazilian Amazonia. It was characterized 262 accessions using 21 qualitative descriptors. The multiple-correspondence analysis (MCA) technique was applied using the criteria: contribution of the descriptor in the last factorial axis of analysis in successive cycles (SMCA); reverse order of the descriptor's contribution in the last factorial axis of analysis with all descriptors ('O' 'p') of Jolliffe's method; mean of the contribution orders of the descriptor in the first three factorial axes in the analysis with all descriptors ('Os') together with ('O' 'p'); and order of contribution of weighted mean in the first three factorial axes in the analysis of all descriptors ('Oz'). The dissimilarity coefficient was measured by the method of multicategorical variables. The correlation among the matrix generated with all descriptors and matrices based on each criteria varied $(r=0.21, r=0.97, r=0.98, r=0.13$ for SMCA, 'Os', 'Oz' and 'O' $\mathrm{p}$ ', respectively). The least informative descriptors were
\end{abstract}

Genetics and Molecular Research 16 (2): gmr16029595 
discarded independently and according to both 'Os' and 'Oz' criteria. Thirteen descriptors were capable to discriminate the accessions and to represent the morphological variability of accessions sampled in Brazilian Eastern Amazonia: color of apical leaves, petiole color, color of stem exterior, external color of storage root, color of stem cortex, color of root pulp, texture of root epidermis, color of leaf vein, color of stem epidermis, color of end branches of adult plant, branching habit, root shape, and constriction of root.

Key words: Multiple correspondence analysis; Manihot esculenta; Genetic resources

\section{INTRODUCTION}

Cassava (Manihot esculenta Crantz) is grown and consumed mainly on tropical and subtropical countries (Howeler et al., 2013). The species is known as an important source of carbohydrate, due to the high content of starch in its tuberous roots (Ceballos et al., 2004). The extended use of cassava is due to its high genetic diversity, and Brazil is the most probable center of origin and domestication (Olsen, 2004; Léotard et al., 2009). The genetic variability of cassava is being maintained in germplasm banks placed on different regions of Brazil (Fukuda et al., 2002), and conservation and availability of this variability to genetic breeding programs are essential in the development and selection of improved genotypes.

Thus, the organization and maintenance of genetic resources of the species, considering the activities of collecting, characterization and conservation, are essential to sustain the genetic basis of genetic breeding programs. The characterization of accessions is made by using morphological, agronomic, and molecular descriptors. Several studies of genetic characterization of cassava accessions (Cardoso and Farias-Neto, 2003; Siqueira et al., 2010; Vieira et al., 2013) use only part of the available phenotypic descriptors, since the characterization is laborious and time-consuming (Oliveira et al., 2014). Besides, the use of many descriptors can generate redundant information (Daher et al., 1997), due to high correlation rates among some traits or low genetic diversity. Thus, some available descriptors can be less informative to discriminate accessions (Alves et al., 2003; Silva et al., 2013; Afonso et al., 2014).

More reliable and less time and cost-consuming methods to characterize accessions of germplasm banks are important to measure genetic variability and the use of minimal highly informative descriptors can be more adequate (Strapasson et al., 2000; Oliveira et al., 2012, 2014). The use of multivariate analysis has been efficient, considering the identification of the most informative descriptors and the least relevant, the ones that should be discarded in the analysis of genetic variability. Some efforts to select the most informative descriptors for cassava has been described (Vendramini et al., 2011; Afonso et al., 2014; Oliveira et al., 2014). However, due to the wide distribution of cassava due to its capacity to adapt to different environments, it is important to evaluate if there are differences among the most informative descriptors to describe samples from different locations.

The aim of this study was to select the most informative morphoagronomical descriptors to characterize and discriminate accessions of the germplasm bank of cassava of Eastern Amazon and to compare the efficiency of adopted criteria to select the descriptors.

Genetics and Molecular Research 16 (2): gmr16029595 


\section{MATERIAL AND METHODS}

Two hundred and sixty-two accessions of cassava that belong to the Regional Germplasm Bank of Eastern Amazon, situated in Belém, Pará, Brazil, were characterized in distinct years. The accessions are representative of samples realized in areas of family farmers, mostly in states of the North region of Brazil, representing the Eastern Amazon, especially on the State of Pará, followed by samples carried out in the State of Amapá. There are some accessions sampled in states of Western Amazonia: Rondônia and Amazonas; from the Northeast: Bahia, Maranhão, Paraíba, Pernambuco, and Sergipe; from Southeast region: São Paulo; South region: Paraná; and the Federal District.

The accessions are disposed in simple lanes, each with nine plants per accession, plot spacing $1.0 \times 1.0 \mathrm{~m}$ and they are renewed when they reach 12 to 14 months old. Grown practices followed the recommendations of Souza et al. (2006). The characterization and evaluation were held on useful plants of each experimental plot after the elimination of borders, considering the mode for 21 morphoagronomic descriptors established for Fukuda and Guevara (1998) (Table 1). The characterization of the 262 accessions was used to establish the list of the most informative descriptors.

Table 1. List of the 21 morphoagronomic descriptors used for the germplasm characterization of the 262 accessions of cassava (Manihot esculenta) from a Germplasm Bank in Brazilian Eastern Amazon, with the respective codes for each descriptors and number of defined categories in the descriptor manual $(\mathrm{k})$.

\begin{tabular}{|c|c|c|}
\hline Descriptors & Code & $\mathrm{k}$ \\
\hline \multicolumn{3}{|l|}{ Mininum descriptors } \\
\hline 1. Color of apical leaves & ColApLea & 4 \\
\hline 2. Pubescence on apical leaves & PuApLea & 2 \\
\hline 3. Petiole color & PetCol & 6 \\
\hline 4. Flowering & Flow & 2 \\
\hline 5. Color of stem cortex & ColStCor & 3 \\
\hline 6. Color of stem exterior & ColStEx & 7 \\
\hline 7. Presence of penduncle roots & PrPeRoo & 3 \\
\hline 8. External color of storage root & ExColRoo & 4 \\
\hline 9. Color of root cortex & ColRooCor & 4 \\
\hline 10. Color of root pulp & ColRooPu & 4 \\
\hline 11. Texture of root epidermis & TexRooEp & 2 \\
\hline \multicolumn{3}{|l|}{ Principal descriptors } \\
\hline 12. Color of leaf vein & ColLeaVe & 4 \\
\hline 13. Number of leaf lobes & NLeaLo & 5 \\
\hline 14. Color of stem epidermis & ColStEp & 4 \\
\hline 15. Color of end branches of adult plant & ColBraAPl & 3 \\
\hline \multicolumn{3}{|l|}{ Secondary descriptors } \\
\hline 16. Branching habit & BraHab & 4 \\
\hline 17. Root shape & RooSh & 4 \\
\hline 18. Constriction of root & ConsRoo & 3 \\
\hline 19. Shape of plant & ShPl & 4 \\
\hline \multicolumn{3}{|l|}{ Preliminary agronomic descriptors } \\
\hline 20. Periderm: ease of peeling & PerEasPel & 2 \\
\hline 21. Cortex: ease of peeling & CorEasPel & 2 \\
\hline
\end{tabular}

The multiple-correspondence analysis (MCA) technique (Escofier and Pages, 1992) was used with the aim to select the minimum descriptors, which is similar to the technique of principal components, but suitable for categorical data. The selection of the most informative descriptors was based on four criteria established by the MCA technique results, according to methodology used by Silva et al. (2013) and Oliveira et al. (2014) and detailed below.

Genetics and Molecular Research 16 (2): gmr16029595 
The MCA based on SMCA criteria was carried out in successive cycles of analyses, where the descriptor of the highest contribution in the last factorial axis in the previous analyses was discarded from posterior analyses, and reordination of descriptors was carried out using the greater contribution of the last factorial axis for each analysis. The analysis was initiated with all the descriptors.

The Jolliffe method for the 'O' $\mathrm{p}$ ' criterium was established based on the inverse contribution of each descriptor on the 21 st factorial axis of the analysis with all the descriptors. The descriptor with the highest contribution in the last factorial axis can be discarded, since the importance of factorial axis decreases from the first to the last one (Jolliffe, 1973).

The 'Os' criterium was measured using selection based on the mean of the contribution orders of the descriptor on the first three factorial of the analysis with all descriptors, considering the value of 'O' $\mathrm{p}$ ', according to the expression: 'Os' $=\left(\mathrm{O} 1+\mathrm{O} 2+\mathrm{O} 3+{ }^{\prime} \mathrm{O}\right.$ ' $\mathrm{p}$ ' $) / 4$.

The selection based on the weighted mean of the contribution orders of the descriptor on the first three factorial axes, with weights (w1 + w2 + w3) corresponded, respectively, to the first three individual eigenvalues, was used to compose the 'Oz' criterium. The analysis was carried out with all the descriptors and it was used the expression: 'Oz' $=(\mathrm{w} 1 . \mathrm{O} 1+\mathrm{w} 2 . \mathrm{O} 2$ $+\mathrm{w} 3 . \mathrm{O} 3) /(\mathrm{w} 1+\mathrm{w} 2+\mathrm{w} 3)$. All analyses were performed in the SPSS 20.0 software (Fávero et al., 2009).

The initial list with the most informative descriptors was adopted for 12 descriptors and the efficiency of the selected criteria was evaluated using correlations between the distance matrix generated with all descriptors and matrices generated by each criterium, obtained with the most informative descriptors. Thus, to measure genetic dissimilarities, the qualitative data of 262 accessions were converted to binary data (present $=1$; absent $=0$ ) for each phenotypic class of all descriptors according to Cole-Rodgers et al. (1997). The significance of correlations between matrices of distance was performed by the $t$-test and the Mantel test with 10,000 permutations (Mantel, 1967). The GENES 5.1 program was used (Cruz, 2006).

The final list with the most informative descriptors was not stablished based on one only criterium, but using comparative analysis of at least two criteria, with the adoption of the highest correlation among matrices. It was considered to discard the common descriptors on both methods and the ones that were less informative.

\section{RESULTS AND DISCUSSION}

The rankings for the most informative descriptors evaluated for 262 accessions of cassava for the criteria SMCA, 'Os', 'Oz', and 'O' 'p' and the respective results are based on MCA and are presented in Table 2. The contribution on the first three factorial axes considering the analysis with the 21 descriptors showed that $50 \%$ of the descriptors with wide contribution were responsible for more than $90 \%$ of total variation associated with each factorial axis.

The MCA results with the 21 descriptors are listed in a supplementary table (Table S1). Silva et al. (2013) evaluated accessions of Capsicum spp characterized with 56 morphological traits and identified similar results. Oliveira et al. (2014) evaluated 95 accessions of cassava using 48 morphoagronomical traits and observed that $62 \%$ of descriptors with wide contribution were responsible for approximately $90 \%$ of total variation. The result of the present study can be an indicative of the existence of redundancy among descriptors, and some descriptors may represent the same information about the genetic variation of accessions.

It was observed, considering SMCA criteria and initial analysis with 21 descriptors,

Genetics and Molecular Research 16 (2): gmr16029595 
Table 2. The 12 most informative morphoagronomic descriptors for 262 accessions of cassava (Manihot esculenta) of a germplasm bank in Brazilian Eastern Amazon ranked by: successive multiple-correspondence analysis (SMCA), the Jolliffe method ('O' 'p'), average contribution to the first three factorial axes and value of the Jolliffe method ('Os'), and weighted contribution to the first factorial axes ('Oz').

\begin{tabular}{|c|c|c|c|c|c|c|c|c|}
\hline Descriptors & Rank & SMCA (\%) & Rank & 'Os' (\%) & Rank & 'Oz' (\%) & Rank & 'O'p' (\%) \\
\hline ColApLea & 14 & 21.00 & 5 & 13.22 & 8 & 13.11 & 19 & 12.00 \\
\hline PuApLea & 18 & 24.30 & 21 & 0.80 & 21 & 1.10 & 1 & 0.00 \\
\hline PetCol & 16 & 44.00 & 4 & 14.70 & 6 & 14.56 & 20 & 12.30 \\
\hline Flow & 2 & 49.30 & 18 & 3.43 & 20 & 3.87 & 6 & 1.00 \\
\hline ColStCor & 7 & 45.00 & 16 & 4.85 & 17 & 4.98 & 11 & 4.00 \\
\hline ColStEx & 19 & 18.00 & 20 & 2.39 & 2 & 29.39 & 17 & 10.00 \\
\hline PrPeRoo & 10 & 30.60 & 17 & 3.50 & 15 & 7.92 & 14 & 5.70 \\
\hline ExColRoo & 6 & 39.40 & 2 & 20.10 & 3 & 28.13 & 8 & 2.10 \\
\hline ColRooCor & 8 & 58.90 & 7 & 12.50 & 7 & 14.50 & 13 & 5.40 \\
\hline$\overline{\mathrm{ColRooPu}}$ & 9 & 62.90 & 13 & 8.35 & 12 & 8.96 & 12 & 4.20 \\
\hline TexRooEp & 1 & 0.00 & 6 & 12.58 & 5 & 18.46 & 5 & 0.90 \\
\hline ColLeaVe & 11 & 49.00 & 12 & 8.63 & 11 & 9.80 & 10 & 3.60 \\
\hline NLeaLo & 20 & 30.00 & 14 & 6.35 & 16 & 5.16 & 16 & 8.00 \\
\hline ColStEp & 5 & 41.40 & 1 & 26.57 & 1 & 36.86 & 9 & 2.70 \\
\hline ColBraAPl & 17 & 20.00 & 8 & 12.27 & 9 & 13.00 & 15 & 7.00 \\
\hline BraHab & 12 & 25.30 & 3 & 18.85 & 4 & 24.24 & 7 & 1.80 \\
\hline RooSh & 13 & 24.50 & 10 & 9.00 & 10 & 11.60 & 4 & 0.20 \\
\hline ConsRoo & 15 & 32.20 & 9 & 9.30 & 14 & 8.90 & 18 & 11.00 \\
\hline$\overline{\mathrm{ShPl}}$ & 21 & 22.40 & 11 & 8.65 & 19 & 4.40 & 21 & 22.40 \\
\hline PerEasPel & 4 & 27.00 & 15 & 5.90 & 13 & 8.92 & 3 & 0.20 \\
\hline CorEasPel & 3 & 46.30 & 19 & 3.25 & 18 & 4.53 & 2 & 0.10 \\
\hline
\end{tabular}

ColApLea $=$ color of apical leaves; PuApLea $=$ pubescence on apical leaves; PetCol = petiole color; Flow $=$ flowering; ColStCor $=$ color of stem cortex; ColStEx $=$ color of stem exterior; PrPeRoo = presence of peduncle roots; ExColRoo = external color of storage root; ColRooCor $=$ color of root cortex; ColRooPu = color of root pulp; TexRooEp = texture of root epidermis; ColLeaVe = color of leaf vein; NLeaLo = number of leaf lobes; ColStEp = color of stem epidermis; ColBraAPl = color of end branches of adult plant; BraHab = branching habit; ConsRoo = constriction of root; RooSh = root shape; $\mathrm{ShPl}=$ shape of plant; PerEasPel = periderm: ease of peeling; CorEasPel $=$ cortex: ease of peeling.

that the trait shape of plant was the one that most contributed in the last factorial axis (22.40) (Table 2). In general, it is the least important descriptor for the characterization of accessions, and this result was an indicative that the information associated with shape of plant is connected with other descriptors associated with other factorial axes. In addition, the descriptor shape of plant showed low contributions in the first factorial axes (second and third factorial axes, 15th and 17th positions of contribution for variation, respectively). The ranking of contribution on the three first factorial axes of the complete model is in Table S1. This result for shape of plant corroborates with the minor importance of the descriptor for total variation. Other descriptors also presented similar results, such as number of leaf lobes, which had the second highest contribution to the last factorial axis, considering SMCA criteria (30.00; Table 2) and low contributions in the second and third factorial axes (16th and 14th positions, respectively). The descriptor pubescence on apical leaves presented the fourth highest contribution on the last factorial axis (24.30; Table 2), according to SMCA criteria, and low contributions on the first three factorial axes (17th, 21st, and 18th positions, respectively). Afonso et al. (2014), when evaluated 200 accessions of cassava using morphological descriptors also identified low genetic variability of pubescence on apical leaves.

On the other hand, the descriptor color of end branches of adult plant showed the fifth highest contribution in the last factorial axis according to SMCA criteria (20.00; Table 2), which indicates a least important contribution for total variation, but, showed higher values

Genetics and Molecular Research 16 (2): gmr16029595 
of contributions on the first two and three factorial axes (3rd and 6th positions, respectively). Similar results were obtained for the descriptors: petiole color, which presented high contributions on the second and third factorial axes (6th and 3rd positions, respectively); color of apical leaves, which presented high contribution on the third factorial axis (5th position), and branching habit, which obtained high contributions on the first three factorial axes (6th, 2nd and 2nd, respectively).

The 12 most informative descriptors according to SMCA criteria (Table 2) were used to obtain the dissimilarity matrix, which was correlated to the dissimilarity matrix generated with all descriptors. It was verified low significant correlation $(\mathrm{P}<0.01)$ based on the $t$-test and the Mantel test among matrices $(\mathrm{r}=0.21)$ (Figure 1A). This low value of correlation is an indicative of low adjustment among matrices after the removal of less informative descriptors according to SMCA criteria adopted for 21 descriptors. The descriptors root shape, color of apical leaves, constriction of root, color of end branches of adult plant, and color of stem exterior were important for the genetic variation, once they showed relevant contributions on the first factorial axes, which reflected on the results of 'Os' or 'Oz' criteria, or on both (Table 2).

Considering the contribution of descriptors on the first three factorial axes, using the 'Os' criterium, the descriptors color of root pulp, number of leaf lobes, periderm: ease of peeling, color of stem cortex, presence of peduncle roots, flowering, cortex: ease of peeling, color of stem exterior, and pubescence on apical leaves were considered low informative. The matrix of distance generated with all the descriptors and correlated with the matrix obtained with the most informative descriptors showed a high magnitude correlation $(\mathrm{r}=0.97 ; \mathrm{P}<0.01)$ according to the $t$-test and the Mantel test (Figure 1B).

The selection of descriptors based on the 'Oz' criterium indicated that periderm: ease of peeling, constriction of root, presence of peduncle roots, number of leaf lobes, color of root cortex, cortex: ease of peeling, shape of plant, flowering, and pubescence on apical leaves were few informative for the discrimination of accessions. It was identified high correlation ( $\mathrm{r}$ $=0.98 ; \mathrm{P}<0.01)$ for the $t$-test and the Mantel test among the distance matrix generated with all descriptors and among the matrix generated with the descriptors selected based on the 'Oz' criterium (Figure 1C). The high values of correlations for both 'Os' and 'Oz' criteria showed a fine adjustment between the matrices, which indicates that the most informative descriptors are capable to discriminate the accessions of cassava.

The 'O' $\mathrm{O}$ ' criterium indicated that the descriptors color of root cortex, presence of peduncle roots, color of end branches of adult plant, number of leaf lobes, color of stem exterior, constriction of root, color of apical leaves, petiole color, and shape of plant were the least informative. The correlation value among the distance matrix generated with all descriptors and the matrix generated with the selected descriptors was low, but significant $(\mathrm{r}=$ $0.13 ; \mathrm{P}<0.01$ ) based on the $t$-test and the Mantel test, which indicated low adjustment among matrices after the removal of the descriptors (Figure 1D).

Silva et al. (2013) identified high and significant correlations $(r=0.80, r=0.89$ and $r=$ 0.87 ) among the matrices generated with all descriptors and matrices obtained with descriptors selected based on 'O' $\mathrm{p}$ ', 'Os', and 'Oz', respectively, on the evaluation of 893 accessions of Capsicum spp. However, the same authors showed results closer to the ones identified in this study, on the evaluation of 106 accessions of Capsicum baccatum, where correlation values were: $r=0.77$ ('O' $\mathrm{O}$ '); $r=0.94$ ('Os'), and $r=0.64$ ('Oz'). On the other hand, Oliveira et al. (2014) identified medium to high correlations among matrices generated after the selection of descriptors on 95 accessions of cassava: $r=0.83$ (SMCA); $r=0.77$ ('Os'); $r=0.75$ ('Oz'); and $r=0.84$ ('O' $\mathrm{p}$ ').

Genetics and Molecular Research 16 (2): gmr16029595 

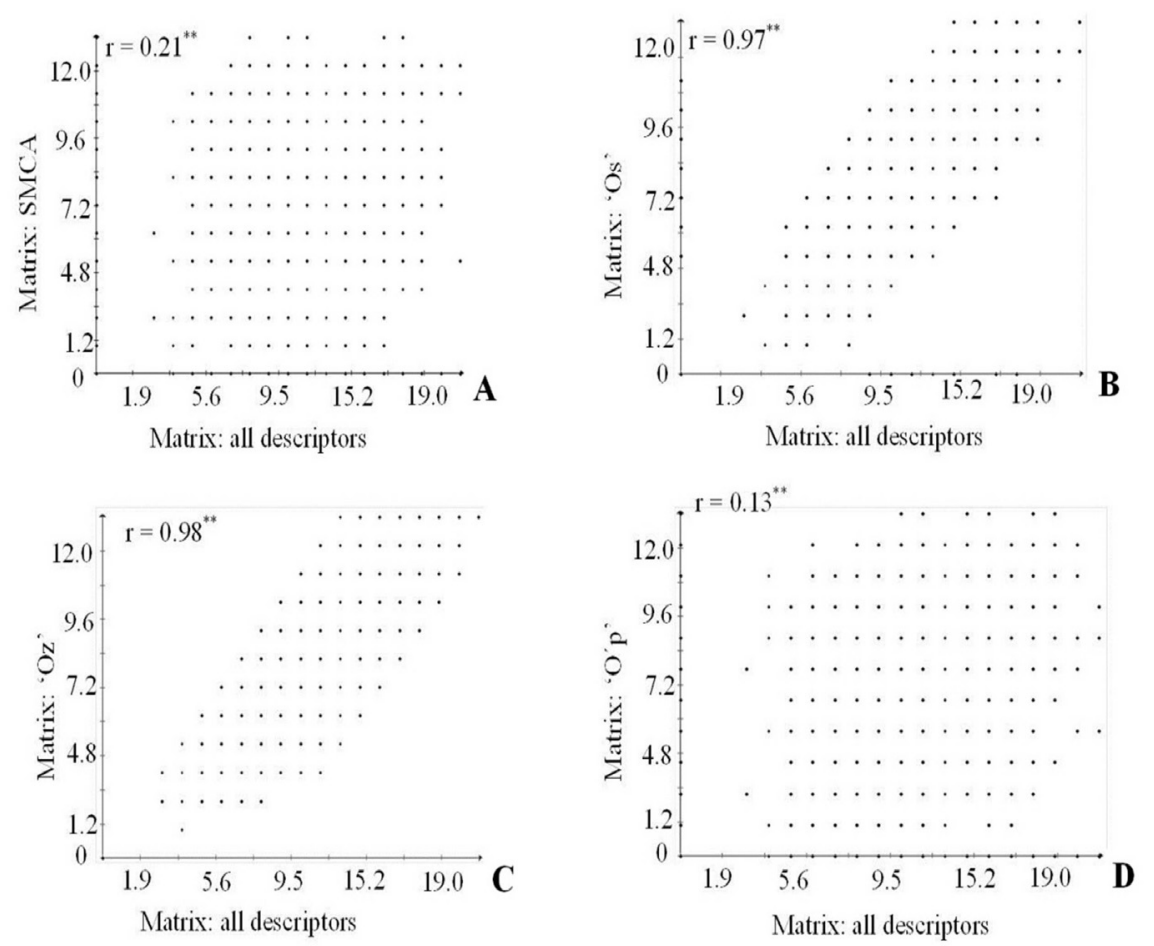

Figure 1. Correlation between the dissimilarity matrices, comparing all the descriptors with those most informative selected by successive multiple-correspondence analysis (SMCA) (A), average contribution to the first three factorial axes and value of the Jolliffe method ('Os') (B), weighted contribution to the first three factorial axes ('Oz') (C), and of the Jolliffe method ('O' 'p') (D). **Significant at $1 \%$ of probability both by $t$ - and by Mantel tests.

Thus, when considering the contribution of descriptors on the first three factorial axes, once the result of correlations among distance matrices based on 'Os' and 'Oz' criteria were high (Figure 1), there is the possibility to discard the descriptors shape of plant, number of leaf lobes, and pubescence on apical leaves, and select the most important descriptors: color of end branches of adult plant, petiole color, color of apical leaves, and branching habit to study the variability of cassava sampled in the North region.

In general, according to Oliveira et al. (2014), there is incompatibility on the exclusion of descriptors using the four criteria. In this study, the 'Os' and 'Oz' criteria were used to discard the following descriptors, since they were considered less informative: number of leaf lobes, periderm: ease of peeling, color of stem cortex, presence of peduncle roots, flowering, cortex: ease of peeling and pubescence on apical leaves. The descriptor shape of plant was also considered in the list of discarded descriptors since it showed low importance for variation (Table 2). The decision to consider different criteria instead of discarding descriptors based on only one criterium was adopted by Oliveira et al. (2014), who discarded 16 of 48 descriptors analyzed for cassava.

The exclusion of descriptors using more than one method was also used in studies with quantitative descriptors. According to Oliveira et al. (2014), the inconstant decision towards the redundant descriptors is leading authors to adopt more than one method and to consider the 
consistency of the results among methods in order to choose the most informative descriptors. Afonso et al. (2014) discarded five quantitative descriptors of 16 evaluated, with the use of principal components and the methods of Singh and Jolliffe. Similar results were shown for other cultures, such as Castro et al. (2012), who evaluated the discrimination capacity and the selection of minimum quantitative descriptors for the characterization and evaluation of passion fruit accessions using principal components techniques. Oliveira et al. (2006) eliminated six of 28 quantitative morphoagronomical descriptors evaluated on 87 progenies of Euterpe oleracea using two procedures based on principal component techniques. According to the authors, the elimination of descriptors did not lead to loss of information. However, Silva et al. (2013), when evaluated the criteria based on multiple correspondence, chose the final descriptors based on the 'Os' criterium, which presented the highest correlation among matrices.

In addition to it, Afonso et al. (2014), when evaluated 19 morphological characters for cassava accessions, selected the nine most informative based on entropy level, which included: color of stem exterior, root shape, petiole color, color of apical leaves, shape of central lobule of the leaf, branching habit, color of root cortex, external color of the root, and color of end branches of adult plant. Vendramini et al. (2011), when evaluated 38 cassava accessions from Mato Grosso, Brazil, using 40 morphological and agronomic descriptors, concluded that there is the possibility to optimize the use of morphoagronomical descriptors with the exclusion of the minimum descriptors described by Fukuda and Guevara (1998). Among the seven descriptors discarded in this study, four are considered minimum descriptors according to Fukuda and Guevara (1998) classification (Table 1). The final list with the most informative descriptors for the characterization of cassava sampled in the Eastern Amazon is in Table 3 and contains 13 descriptors, of which seven are minimum descriptors, three are principal, and three are secondary.

Table 3. List of the most informative descriptors for the characterization of cassava (Manihot esculenta) germplasm sampled in the Eastern Amazon, Brazil.

\begin{tabular}{l|l}
\hline Descriptors & Code \\
\hline Minimum descriptors & \\
\hline 1. Color of apical leaves & ColApLea \\
\hline 2. Petiole color & PetCol \\
\hline 3. Color of stem exterior & ColStEx \\
\hline 4. External color of storage root & ExColRoo \\
\hline 5. Color of stem cortex & ColStCor \\
\hline 6. Color of root pulp & ColRooPu \\
\hline 7. Texture of root epidermis & TexRooEp \\
\hline Principal descriptors & \\
\hline 8. Color of leaf vein & ColLeaVe \\
\hline 9. Color of stem epidermis & ColStEp \\
\hline 10. Color of end branches of adult plant & ColBraAPl \\
\hline Secondary descriptors & \\
\hline 11. Branching habit & BraHab \\
\hline 12. Root shape & RooSh \\
\hline 13. Constriction of root & ConsRoo \\
\hline
\end{tabular}

Oliveira et al. (2014) selected the 32 most informative descriptors to characterize the accessions of cassava, and 14 of these were selected in this study: color of apical leaves, petiole color, color of stem cortex, color of root pulp, flowering, number of leaf lobes, color of end branches of adult plant, constriction of root, color of leaf vein, branching habit, root shape, shape of plant, periderm: ease of peeling, and cortex: ease of peeling. On the other hand, the descriptors: flowering, shape of plant, periderm: ease of peeling, and cortex: ease of peeling

Genetics and Molecular Research 16 (2): gmr16029595 
were not selected as the most informative in this study. This present study was based mainly on cassava genotypes sampled in the North region, especially in the State of Pará. Perhaps the importance of the descriptors varies according to the nature of the sample, which may be an effect of natural or artificial pressure of selection on some of the traits.

The correlation among the matrix generated with all descriptors and the one obtained with the 13 selected descriptors showed high and significant correlation with both tests: $t$ - and Mantel $(\mathrm{r}=0.98 ; \mathrm{P}<0.01)$ (Figure 2), and the most informative descriptors were capable of discriminating the cassava accessions, contributing to evaluate the genetic divergence among them. Besides, the exclusion of $38 \%$ of the 21 descriptors represents time and costs saving, in addition to the optimization of the management of cassava germplasm collections in the Amazon region. Silva et al. (2013) discarded 50\% of the initial descriptors of Capsicum spp; Oliveira et al. (2012) discarded $25 \%$ of the 21 multicategorical descriptors used in the characterization of papaya accessions, and Oliveira et al. (2014) discarded 37\% of the initial 51 descriptors of cassava.

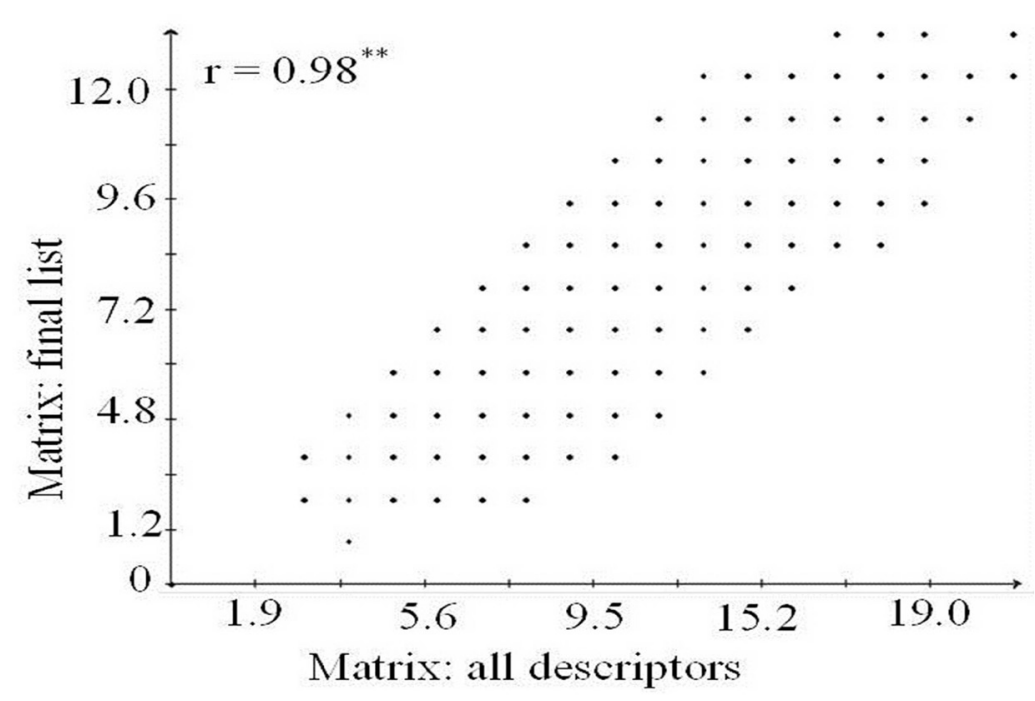

Figure 2. Correlation between the dissimilarity matrices, comparing all the descriptors and the final list of the most informative selected. ${ }^{*}$ Significant at $1 \%$ of probability both by $t$ - and by Mantel tests.

It is worth noticing that, when the objective is to select the best accessions for genetic breeding purposes, it is important to evaluate agronomical traits with economic importance. Shape of plant, for example, is a trait that influences the spacing among plants and flowering is also important, since cassava needs to ramify to start flowering. Thus, the selection of the most informative descriptors is important to describe the germplasm and to estimate genetic diversity and it saves time and money when the purpose is to organize germplasm information.

Thus, the list of the most informative qualitative descriptors allows the characterization of cassava accessions conserved on the Germplasm Bank of Eastern Amazon, in order to represent the morphological variation and the characterization of accessions of the germplasm sampled in the Eastern Amazon.

Genetics and Molecular Research 16 (2): gmr16029595 


\section{ACKNOWLEDGMENTS}

The authors thank the National Council of Technological and Scientific Development (CNPq, process \#408042/2013-3), the Brazilian Agricultural Research Corporation (Embrapa, project \#0115020021206), the Amazon Research Foundation (FAPESPA, process \#ICAAF 145/2014), and the Federal Rural University of Amazonia for the support for activities.

\section{REFERENCES}

Afonso SD, Ledo CAS, Moreira RFC, Silva SO, et al. (2014). Selection of descriptors in a morphological characteristics considered in cassava acessions by means of multivariate techniques. IOSR-JAVS 7: 13-20. http://dx.doi. org $/ 10.9790 / 2380-07151320$

Alves RM, Garcia AF, Cruz ED and Figueira A (2003). Seleção de descritores botânico-agronômicos para caracterização de germoplasma de cupuaçuzeiro. Pesq. Agr. Bras 38: 807-818.

Cardoso EMR and Farias-Neto JT (2003). Diversidade genética entre acessos de mandioca avaliados a partir de caracteres morfoagronômicos. Rev. Cienc. Agrar. (Belem.) 39: 109-121.

Castro JA, Neves CG, Jesus ON and Oliveira EJ (2012). Definition of morfo-agronomic descriptors for the characterization of yellow passion fruit. Sci. Hortic. (Amsterdam) 145: 17-22. http://dx.doi.org/10.1016/j.scienta.2012.07.022

Ceballos H, Iglesias CA, Pérez JC and Dixon AGO (2004). Cassava breeding: opportunities and challenges. Plant Mol. Biol. 56: 503-516. http://dx.doi.org/10.1007/s11103-004-5010-5

Cole-Rodgers P, Smith DW and Bosland PW (1997). Anovel statistical approach to analyze genetic resource evaluations using capsicum as an example. Crop Sci. 37: 1000-1002. http://dx.doi.org/10.2135/cropsci1997.0011183X003700030050x

Cruz CD (2006). Programa GENES: Análise multivariada e simulação. UFV, Viçosa.

Daher RF, Moraes CF, Cruz CD, Pereira AV, et al. (1997). Seleção de caracteres morfológicos discriminantes em capimelefante (Pennisetum Purpureum Schum). Rev. Bras. Zootec. 26: 265-270.

Escofier B and Pages J (1992). Análisis fatoriales simples y múltiples: objetivos, métodos e interpretación. Servicio Editorial de la Universidad del País Vasco, Bilbão.

Fávero LP, Belfiore P, Silva FL and Chan BL (2009). Análise de dados: modelagem multivariada para tomada de decisões. Elsevier, Rio de Janeiro.

Fukuda WMG and Guevara CL (1998). Descritores morfológicos e agronômicos para caracterização de mandioca (Manihot esculenta Crantz). Documento 78. Embrapa Mandioca Fruticultura, Cruz das Almas.

Fukuda WMG, Silva SO and Iglesias I (2002). Cassava breeding. Crop Breed. Appl. Biotechnol. 2: 617-638. http://dx.doi. org/10.12702/1984-7033.v02n04a18

Howeler R, Lutaladio N and Thomas G (2013). Save and Grow Cassava: a guide to sustainable production intensification. FAO, Rome.

Jolliffe IT (1973). Discarding variables in a principal component analysis. II. Real data. J. R. Stat. Soc. Ser. C Appl. Stat. 22: 21-31.

Léotard G, Duputié A, Kjellberg F, Douzery EJP, et al. (2009). Phylogeography and the origin of cassava: new insights from the northern rim of the Amazonian basin. Mol. Phylogenet. Evol. 53: 329-334. http://dx.doi.org/10.1016/j. ympev.2009.05.003

Mantel N (1967). The detection of disease clustering and a generalized regression approach. Cancer Res. 27: 209-220.

Oliveira EJ, Oliveira GAF, Costa JL, Oliveira VJS, et al. (2012). Genetic diversity and marker-assisted inbreeding in papaya. Sci. Hortic. (Amsterdam) 147: 20-28. http://dx.doi.org/10.1016/j.scienta.2012.08.031

Oliveira EJ, Filho OSO and Santos VS (2014). Selection of the most informative morphoagronomic descriptors for cassava germplasm. Pesq. Agr. Bras 49: 891-900. http://dx.doi.org/10.1590/S0100-204X2014001100008

Oliveira MSP, Ferreira DF and Santos SB (2006). Seleção de descritores para a caracterização de açaizeiro para produção de frutos. Pesq. Agr. Bras 41: 1133-1140. http://dx.doi.org/10.1590/S0100-204X2006000700009

Olsen KM (2004). SNPs, SSRs and inferences on cassava's origin. Plant Mol. Biol. 56: 517-526. http://dx.doi.org/10.1007/ s11103-004-5043-9

Silva WCJ, Carvalho SIC and Duarte JB (2013). Identification of minimum descriptors for characterization of Capsicum spp. germplasm. Hortic. Bras. 31: 190-202. http://dx.doi.org/10.1590/S0102-05362013000200004

Siqueira MVBM, Pinheiro TT, Borges A, Valle TL, et al. (2010). Microsatellite polymorphisms in cassava landraces from the Cerrado biome, Mato Grosso do sul, Brazil. Biochem. Genet. 48: 879-895. http://dx.doi.org/10.1007/s10528$\underline{010-9369-5}$

Genetics and Molecular Research 16 (2): gmr16029595 
Souza LS, Farias ARN, Mattos PLP and Fukuda WMG (2006). Aspectos socioeconômicos e agronômicos da mandioca. CNPMF, Cruz das Almas.

Strapasson E, Vencovsky R and Batista LAR (2000). Seleção de descritores na caracterização de germoplasma de Paspalum sp. por meio de componentes principais. Rev. Bras. Zootec. 29: 373-381. http://dx.doi.org/10.1590/S1516$\underline{35982000000200008}$

Vieira EA, Fialho JF, Faleiro FG, Bellon G, et al. (2013). Caracterização fenotípica e molecular de acessos de mandioca de indústria com potencial de adaptação às condições do Cerrado do Brasil Central. Semin. Cienc. Agrar. 34: 567-582. http://dx.doi.org/10.5433/1679-0359.2013v34n2p567

Vendramini JM, Neves LG, Barelli MAA, Elias JCF, et al. (2011). Otimização do uso dos descritores morfoagronômicos de mandioca em análise multivariada. Cienc. Agron. 42: 906-913. http://dx.doi.org/10.1590/S1806-66902011000400012

\section{Supplementary material}

Table S1. Contribuition of the 21 morphoagronomic descriptors used for the morphological characterization of 262 accessions of Manihot esculenta from a germplasm bank in Brazilian Eastern Amazon, with the dimensions and their respective eigenvector, eignvalues and percentage of variation.

Genetics and Molecular Research 16 (2): gmr16029595 